\title{
Public Funding of Political Parties
}

\author{
IGNACIO ORTUNO-ORTÍN \\ University of Alicante \\ CHRISTIAN SCHULTZ \\ University of Copenhagen
}

\begin{abstract}
This paper studies the typical European system for public funding of parties, where parties receive public funds depending on their vote share. These funds finance electoral campaigns. It is shown that such a funding system increases policy convergence. The effect is larger, the more funding depends on vote shares. If the parties have access to other means of campaign finance given in a lump-sum way, the effect is moderated.
\end{abstract}

\section{Introduction}

The funding of political parties is a fundamental aspect of democracy. Most countries have some sort of public funding, but the way it is provided varies considerably. In many European countries parties receive public funding in relation to the share of the electoral vote they achieved in the last election. ${ }^{1}$ This paper investigates such public funding systems. While the debate about public funding has often focused on fairness and on reducing the power

Ignacio Ortuno-Ortín, Department of Economics, University of Alicante, and IVIE, 03071Alicante, Spain (Ortin@merlin.fae.ua.es). Christian Schultz, Institute of Economics, University of Copenhagen, Studiestraede 6, DK-1455 Copenhagen K., Denmark and CIE, EPRU and CES-ifo (cs@econ.ku.dk).

We are grateful to Enriqueta Aragones, David Baron, John Brehm, Iñigo Irtube, Vijay Krishna, Jorge Streb, David Strömberg, Fabrizio Zilibotti, and many seminar audiences for comments and suggestions. Ortuno-Ortin gratefully acknowledges financial support from the Spanish Ministry of Education through grant CICYT PB-970131.

${ }^{1}$ Le Duc et al. (1996) report that in 17 (of 27) countries, public funding depends on vote (or seat) share. In Denmark, for example, one vote gives about 20 Danish kroner (around US \$3) per year. Bille (1997) notes that public funding has increased dramatically in the 1990s. He finds that it accounts for 48-98\% of major Danish parties' income. Mair (1994) finds that in many European countries public finance is at least as important for political parties as private finance is. 
of wealthy private lobbies, we show that an important consequence of the "European" system is policy convergence. The more public funding parties receive, the more policy convergence will result.

In the model of the paper, parties spend money on electoral campaigns. There is substantial empirical evidence to support the hypothesis that electoral campaigns affect how the electorate votes, (see, e.g., Holbrook 1996). This may work in several ways. Baron (1994) and McKelvey and Ordeshook (1987) suggests that there are two types of voters: "informed" and "uninformed" or "impressionable" voters. The informed voters are policy motivated and cast their votes depending on the policies proposed by the political parties. Impressionable voters are poorly informed about policies (and perhaps uninterested) and their vote is directly influenced by campaign spending. Alternatively, one may assume that all voters are policy motivated but not necessarily well informed about parties' policies. Then campaigns can inform about policies. Here, we follow the lead of Baron (1994). ${ }^{2}$

We consider campaigning in a model with two policy motivated parties and a unidimensional policy space. When some voters are impressionable, a party directly receives more votes if it campaigns more. The public funding system makes the parties' policies converge. The reason for this is intuitive: parties are policy motivated and the likelihood that a party's policy is implemented depends positively on its share of the total vote. This creates a trade-off: a more moderate policy is less preferable for the party but more likely to be implemented. This trade-off is changed by the public funding system. The vote gaining effect of policy moderation is enhanced (as the public funds gained buy even more votes), and in equilibrium, therefore, policies are more moderate. The more responsive votes are to campaigns and the more responsive public funding is to votes, the more the parties' policies converge. For this effect, it is necessary that public funds depend on vote shares.

Public funding depending on the vote share makes policies converge when there are some impressionable voters in the electorate. Whether policies then are more or less close than in a benchmark case, where all voters are policy motivated, depends on whether the impressionable voters are sufficiently responsive and public funds depend enough on the vote share. A precise condition for this is given in the paper.

We also show that if parties have access to other funds given in a lump-sum manner the effects of the type of public funding analyzed here are mitigated, since this funding becomes relatively less important.

For the sake of simplicity, we assume that parties and voters have Euclidian preferences, where the utility is linearly decreasing in the distance from the bliss point, agents are therefore (locally) risk neutral. This, however, is not essential for our qualitative results. If agents are (globally) risk averse, the

${ }^{2}$ The working paper version of this paper, Ortuno-Ortin and Schultz (2000), also considers the case of informative campaigning, we briefly discuss this in the concluding remarks. 
European system for public funding of parties is welfare enhancing, since it reduces policy polarization and, therefore, the general risk for everyone.

The theoretical literature dealing with this type of public funding is scarce. Baron (1994) considers lobbying in a model with informed and impressionable voters, in which parties seek to maximize their probability of winning. If all voters are policy motivated, each party chooses the median voter's most preferred policy. However, as a consequence of the existence of impressionable voters, parties also wish to raise funds. Courting lobby groups, which are generally considered to be extreme, can do this. In their desire to please the lobbies, the parties thus propose more extreme policies. The introduction of public funding (as a lump sum and independent of vote-share), mitigates the power of interest groups and their contributions become relatively less important. As a result, the parties' policies are less polarized.

Our argument does not depend on mitigating lobby groups' power. We consider partisan parties who choose polarized policies even in the absence of lobbies. When public funding depends on vote share, parties get an extra incentive to moderate their policies. When public funding does not depend on the vote share, (as in the US system Baron analyses), there is no policy convergence in our model with impressionable voters. Hence, our analysis shows that the precise sort of public funding system employed is essential to understand its effect on policy convergence.

An early theoretical contribution about the effects of campaigns financed by private money is Austen-Smith (1987). Mueller and Stratman (1994) also consider campaigns with a focus on private contributions to political parties. Morton and Cameron (1992) survey some early literature.

The organization of the paper is as follows. Section 2 presents the basic model. Section 3 derives the equilibrium and Section 4 concludes. A few proofs are relegated to the Appendix.

\section{The Model}

There are two parties, $L$ and $R$, and a continuum of voters of measure one. Politics is unidimensional. The parties each propose a policy, $l$ and $r$ respectively, receive campaign money, $c_{L}$ and $c_{R}$, which is spent, and then an election is held. Finally, the winner of the election implements its proposed policy. There are two kinds of voters, informed and impressionable. ${ }^{3}$ Informed voters are informed about policies and cast their vote based on the parties' policies, while impressionable voters are uninformed about policies and cast their vote based on the parties' campaigns. The fraction of informed voters is $(1-$ $\alpha$ ), where $0<\alpha<1$.

\footnotetext{
${ }^{3}$ One could identify informed voters with highly political aware persons and the impressionable voters with less aware persons. Zaller (1992) shows that, in presidential elections, the least aware persons are most susceptible to a persuasive message.
} 
If the policy is $\pi$, an informed voter with bliss point $x$ gets utility

$$
u(\pi ; x)=-|\pi-x| .
$$

The bliss points are distributed on the interval $[0,1]$ according to the cumulative distribution function $F(x)$; the corresponding (strictly positive, differentiable) density is $f(x)$. Let $m$ be the median bliss point, $F(m)=1 / 2$. As $l \leq r$ an informed voter with bliss point $x$ prefers party $L$ 's policy if $x \leq \frac{l+r}{2} .{ }^{4}$ Since voting is sincere, the fraction $F\left(\frac{l+r}{2}\right)$ of the informed voters vote for party $L$. Parties are policy motivated and have the same type of utility function as voters (see Wittman 1990). The bliss point of party $L(R)$ is $x_{L}\left(x_{R}\right)$, and $x_{L}<m<x_{R}$.

The fraction of total campaign spending done by party $L$ is $\Delta \equiv \frac{c_{L}}{c_{L}+c_{R}}$. A fraction $H(\Delta)$ of the impressionable voters vote for party $L$. We will assume that $H^{\prime}>0, H\left(\frac{1}{2}\right)=\frac{1}{2}$, and $H^{\prime \prime}(\Delta) \leq 0$ for all $\Delta \geq \frac{1}{2}$. The party spending most becomes the most popular among uninformed voters. We further assume that the $H$ function is symmetric: $H(\Delta)=1-H\left(\frac{1}{\Delta}\right)$, so $H^{\prime \prime}(\Delta) \geq 0$ for all $\Delta \leq \frac{1}{2}$ and $H^{\prime \prime}\left(\frac{1}{2}\right)=0$.

Party $L$ 's total vote share is therefore

$$
v=\alpha H(\Delta)+(1-\alpha) F\left(\frac{l+r}{2}\right) .
$$

As Grossman and Helpman (1996) do, we assume that a higher vote share increases the chance a party's policy is implemented. It may be due to the fact that the larger a party is, the larger the influence it has in parliament. One might also assume that parties are uncertain about the outcome of the election, either because of polling errors or uncertainty about who will vote and who will abstain. The larger the (ex ante) vote share a party has, the larger is the probability that it wins the election and implements its policy, (see Roemer 1994 for microfoundations). Party $L$ 's policy is implemented with probability $p(v)$, where for simplicity, $p(v)=v$. The linearity simplifies but has no qualitative importance. The steeper the $p$ function at $\frac{1}{2}$ is, the greater is the parties' incentive to moderate their policies.

Parties receive two kinds of funds: public funds based on vote shares and lump-sum funds. The latter could in principle be both public or private, the distinguishing feature is that the amount the party receives of such funds is independent both of the policies and the vote shares. Typical examples are endowments that parties may have or contributions received from different social groups whose overall political tendencies are more in line with the party's, for instance trade unions supporting social democratic parties

\footnotetext{
${ }^{4}$ The parties can also propose policies where $r<l$, but this will never occur in equilibrium, so we disregard this case.
} 
independent of the precise policy. ${ }^{5}$ Let $c_{p}$ be the total amount of lump-sum funds of party $L$ and $R$; for simplicity, we assume that they have $\frac{c_{p}}{2}$ each. We briefly consider the asymmetric case later.

Parties receive funds depending on the vote share obtained in the election. These funds will, therefore, only be available after the election. If a party wishes to spend money before the election it must therefore either take a loan or spend money received in the previous election. We assume that the party has access to a perfect credit market, where it can get a loan to be repaid by the funds earned in the election. The market is supposed to hold rational expectations regarding the vote share of the party. We thus abstract from issues of credit worthiness and the dynamic issues involved if parties only can borrow a fraction of the money they are expected to receive. In most countries parties are in fact heavily indebted before elections.

The timing is as follows. First, the two parties propose policies. Then, they receive public funding depending on their expected vote share. The expectation is correct. This is equivalent to the case in which parties borrow on a perfect credit market with rational expectations before an election and use the public funding they later receive to repay the loans. ${ }^{6}$

Let $c_{g}$ be the size of the public funds. We will assume that parties are treated equally. If party $L$ is expected to receive a share $v^{e}$ of votes, it receives $c_{g L}=\psi\left(v^{e}\right) c_{g}$ from public funding, and party $R$ then receives $c_{g R}=$ $\psi\left(1-v^{e}\right) c_{g}$. Accordingly, $\psi\left(\frac{1}{2}\right)=\frac{1}{2}$. We assume that the funding system fulfills $\psi^{\prime} \geq 0$ for all $v^{e}$ and $\psi^{\prime \prime}\left(v^{e}\right) \leq 0$ for all $v^{e} \geq \frac{1}{2}$, and $\psi^{\prime \prime}\left(v^{e}\right) \geq 0$ for all $v^{e} \leq \frac{1}{2}$. A party that has already obtained $50 \%$ of the votes (weakly) increases its funds at a non-increasing rate by receiving more votes. ${ }^{7}$

If party $L$ is expected to receive a vote share $v^{e}$, the relative fraction of funds received—and spent—by party $L$ is

$$
\Delta\left(v^{e}\right)=\frac{\psi\left(v^{e}\right) c_{g}+\frac{1}{2} c_{p}}{c_{g}+c_{p}} .
$$

Given an expected vote share of $v^{e}$, and a pair of policies $(l, r)$, the actual vote share of party $L$ is

$$
v=\alpha H\left(\Delta\left(v^{e}\right)\right)+(1-\alpha) F\left(\frac{l+r}{2}\right) .
$$

\footnotetext{
${ }^{5}$ Since there is comprehensive literature on private lobbying, and its effects on policymaking are quite well understood it is not included in the model. See Baron (1994), Austen-Smith (1997), Persson and Tabellini (2000), and Grossman and Helpman (2001).

${ }^{6}$ Notice that if parties have access to a perfect credit market, public funding will not prevent the entry of new parties to the political arena. For the time being, however, we disregard the issue of entry.

${ }^{7}$ We may note that the Danish system described in the Introduction, in which a party receives approximately 20 Danish kroner (US\$3) per year per vote, has $\psi^{\prime}>0$ and $\psi^{\prime \prime}=0$.
} 
Under rational expectations, $v^{e}=v$; hence, $v$ solves Equation (3) with $v$ inserted for $v^{e}$. If

$$
\alpha H^{\prime}(\Delta(v)) \Delta^{\prime}(v)<1, \quad \text { for all } v \in[0,1],
$$

the solution is unique. We assume this is the case, and denote the solution by $v(l, r)$. This means that the responsiveness of public funding and of the impressionable voters are sufficiently limited to make the problem well behaved. Note that we are not assuming that the final equilibrium is unique but just that there is a unique vote share for each party for a given pair of policies. The implicit function theorem yields

$$
\frac{\partial v(l, r)}{\partial l}=\frac{\frac{1-\alpha}{2} f\left(\frac{l+r}{2}\right)}{1-\alpha H^{\prime}(\Delta(v)) \Delta^{\prime}(v)}>0 .
$$

When party $L$ changes its policy, some informed voters change their votes. This, in turn, increases the public funds allocated to the party and, therefore, its share of impressionable votes. But this, once again, increases the funds received, etc. These repercussions are taken into account in the rational expectations solution. The assumption $\alpha \Delta^{\prime}(v) H^{\prime}(\Delta(v))<1$ ensures that the comparative statics make sense, i.e., if party $L$ increases its policy (toward the middle), it will increase its vote share.

\section{Political Equilibrium}

The parties are policy motivated and seek to maximize expected utility. They take the other party's policy as given and recognize how the choice of policy might influence the distribution of funds and the relative campaign spending. Given the pair of policies, $(l, r)$, party's $L$ expected utility is

$$
v(l, r)\left(-\left|l-x_{L}\right|\right)+(1-v(l, r))\left(-\left|r-x_{L}\right|\right) .
$$

Similarly, party's $R$ expected utility is given by

$$
v(l, r)\left(-\left|l-x_{R}\right|\right)+(1-v(l, r))\left(-\left|r-x_{R}\right|\right) .
$$

A Political equilibrium with campaigning is a pair of policies $\left(l^{*}, r^{*}\right)$, such that $l^{*}$ maximizes (6) given $r^{*}$ and $r^{*}$ maximizes (7) given $l^{*}$.

In principle, a party's optimal policy may be equal to the party's bliss point where the utility function is non-differentiable. We will, however, only consider interior solutions, where $x_{L}<l<r<x_{R}$. We have

PROPOSITION 1: In an interior political equilibrium with campaigning:

(a) Each party receives half of the votes. 
(b) The expected policy equals the median informed voter's preferred policy

$$
\frac{l^{*}+r^{*}}{2}=m .
$$

(c) The policies are symmetric around $m$ and the policy polarization is

$$
r^{*}-l^{*}=\frac{1-\alpha \frac{\psi^{\prime}\left(\frac{1}{2}\right) c_{g}}{c_{g}+c_{p}} H^{\prime}\left(\frac{1}{2}\right)}{1-\alpha} \frac{1}{f(m)} .
$$

Proof: The first-order condition for party $L$ is

$$
\begin{gathered}
\left(\alpha H^{\prime}(\Delta) \frac{d \Delta}{d l}+\frac{(1-\alpha)}{2} f\left(\frac{l+r}{2}\right)\right)(r-l) \\
-\left(\alpha H(\Delta)+(1-\alpha) F\left(\frac{l+r}{2}\right)\right)=0 .
\end{gathered}
$$

Inserting (5) and using the fact that $\frac{d \Delta}{d l}=\Delta^{\prime}(v(l, r)) \frac{\partial v(l, r)}{\partial l}$ yields

$$
\frac{1}{1-\alpha H^{\prime}(\Delta) \Delta^{\prime}(v)} \frac{f\left(\frac{l+r}{2}\right)}{2}(r-l)-\left(\frac{\alpha}{1-\alpha} H(\Delta)+F\left(\frac{l+r}{2}\right)\right)=0 .
$$

Similarly, the first-order condition for $R$, can be written as

$$
\begin{aligned}
& \frac{1}{1-\alpha H^{\prime}(\Delta) \Delta^{\prime}(v)} \frac{f\left(\frac{l+r}{2}\right)}{2}(r-l) \\
& -\left(\frac{\alpha}{1-\alpha}(1-H(\Delta))+\left(1-F\left(\frac{l+r}{2}\right)\right)\right)=0 .
\end{aligned}
$$

Since the first parts of (11) and (12) are identical, we get $v=$ $\alpha H(\Delta)+(1-\alpha) F\left(\frac{l+r}{2}\right)=\frac{1}{2}$. Since, $\Delta\left(\frac{1}{2}\right)=\frac{1}{2}$, and $H\left(\frac{1}{2}\right)=\frac{1}{2}$, this implies $F\left(\frac{l^{*}+r^{*}}{2}\right)=\frac{1}{2}$, so $(8)$ is fulfilled. Inserting into (11) and rearranging yields $(9)$. Finally using $\frac{l^{*}+r^{*}}{2}=m$, one sees that the policies are symmetric around $m$.

If there were no public funds depending on vote shares, $c_{g}=0$. It follows directly from Equation (9) that public funding depending on vote shares makes the parties' policies converge.

From Equation (9) in Proposition 1 we have Corollary 1.

COROLLARY 1: In an interior political equilibrium with campaigning policy polarization $\left(l^{*}-r^{*}\right)$ decreases in: 
(a) the size of public funds depending on vote shares, $c_{g}$;

(b) the responsiveness of the public funding system as given by $\psi^{\prime}\left(\frac{1}{2}\right)$; and

(c) the responsiveness of the impressionable voters as given by $H^{\prime}\left(\frac{1}{2}\right)$.

Policy polarization $\left(l^{*}-r^{*}\right)$ increases in the size of lump-sum funds, $c_{p}$.

The more public funds depend on vote shares, the larger is the policy convergence. The system gives an extra incentive to moderate policies, since the extra votes gained from moderating policies makes more public funds available, which, in turn can be used to gain further votes. Lump-sum funds tend to moderate this effect. When the parties have access to large lumpsum funds, the extra funds that can be gained through the public funding system by moderating policy become less important. It may be noted that if the impressionable voters' vote depends on the absolute rather than relative difference in funding this would not be true. If the difference is crucial, an equally large lump sum to each of the parties has no effect. We believe our formulation is the more reasonable. The impact of extra $\$ 100,000$ is not independent of whether parties already have campaign budgets totaling millions of dollars or not.

In Baron (1994), parties seek to maximize plurality. With no funding whatever, they choose the median voter's preferred policy. Private funding is provided by extreme lobby groups, who reward the parties for more extreme policies and this makes for policy polarization. Public funds are given in a lump sum (as in the US system), and they reduce the relative importance of lobbies' funds. Consequently policies become more convergent. In our model exactly the opposite result is obtained from lump-sum contributions. Such contributions (whether private or public) decrease the importance of the funds earned through votes, and this makes policies more divergent. In both models lump-sum contributions mitigate the effect of non-lump-sum contributions. Viewed in this perspective, one could say, that the difference is that in Baron's paper variable funds are given by extreme groups in response to more extreme policies; this makes for policy polarization. In a system with public funding depending on vote share variable funds are given in response to more moderate policies; this makes for policy convergence. In both cases lump-sum funds mitigate the effects of variable funds.

If there are no impressionable voters, then $\alpha=0$ and

$$
r^{*}-l^{*}=\frac{1}{f(m)} .
$$

From (9) it follows that if $H^{\prime}\left(\frac{1}{2}\right) \Delta^{\prime}\left(\frac{1}{2}\right)>1$ polices are more convergent than in the benchmark case with no impressionable voters, and if $H^{\prime}\left(\frac{1}{2}\right) \Delta^{\prime}\left(\frac{1}{2}\right)<1$, policies are more divergent. Hence, we cannot it a priori say whether the case of impressionable voters and a public funding system yield more policy convergence than the one obtained in the case with only informed voters. 
Finally, we note that the higher the density of the informed voters at the median voter's preferred policy, the more policy convergence. This is a standard result in the literature. The higher this density, the more votes can be gained by moving policy closer to the middle.

If one extends the model to allow for asymmetric lump-sum funds, it is easily shown that the richest party will choose a more extreme policy, since such a party has a larger share of the impressionable voters it can afford to loose some public funds (see Ortuno-Ortin and Schultz 2000).

In the Appendix, we show that the second-order condition is fulfilled if

$$
\frac{f^{\prime}}{f}<4, \quad \text { and } \quad \frac{d^{2} \Delta}{d l^{2}} / \frac{d \Delta}{d l}+\frac{H^{\prime \prime}}{H^{\prime}}<2 .
$$

The latter part is a joint condition on $\Delta$ and $H$, and it is difficult to provide general conditions that ensure that it is fulfilled. We show in the Appendix, however, that if $H^{\prime \prime}=0$ and $\psi^{\prime \prime}=0$, so $\Delta^{\prime \prime}=0$, those inequalities are fulfilled. As is clear from the derivation, it is not necessary that $H^{\prime \prime}=0$ and $\Delta^{\prime \prime}=0$, but rather that these second derivatives should not be too large.

We have assumed that the equilibrium is interior, $x_{L}<l<r<x_{R}$. This obviously implies that $r-l<x_{R}-x_{L}$. As can be seen from Equation (9) this requires $f(m)$ to be sufficiently large and/or $\left(1-\alpha H^{\prime}\left(\frac{1}{2}\right) \Delta^{\prime}\left(\frac{1}{2}\right)\right) /(1-\alpha)$ to be sufficiently small. An example that fulfills this condition is, $x_{L}=0, x_{R}=$ $1, m=1 / 2, H^{\prime}\left(\frac{1}{2}\right) \Delta^{\prime}\left(\frac{1}{2}\right)=1$ and $f(m)>1$.

If there are more parties with different bliss points, and the probability a party's policy is implemented equals its vote share, similar results as those obtained above continue to hold (again see Ortuno-Ortin and Schultz 2000).

\section{Concluding Remarks}

Public funding of political parties moderate partisan policies. When campaigns are persuasive, and the public funds depend on the vote share, parties have more incentives to moderate their policies. A moderate policy gives more votes and, therefore, higher public funds, which in turn, can be used to buy even more votes. The parties' trade off between preferred policies and electoral success is changed, making moderation a more attractive option.

In the working paper version, Ortuno-Ortin and Schultz (2000), we also consider the case where all voters are policy motivated, but only some are informed about a party's policy. In such a setting, campaigns inform about policies. The more a party spends on its campaign, the larger is the fraction of voters who learn its policy. The gain in vote share from moderating the policy (more than expected) is larger, the larger is the fraction of informed voters, since only these voters will learn about a change in policy. Hence, the incentive to moderate policy is enhanced, the more informed voters there are. It follows that policy convergence will depend on how effective electoral spending is in spreading information, and on the amount of funds available. This effect works regardless of whether public funds depend on the vote 
share or not. The important feature here is that more funds make for more information, which makes for more convergence. Thus, it is the total amount of funds that matter, not the exact way they are distributed. In this way, there is a difference with the case where campaigns are persuasive.

\section{Appendix}

For party $L$ the second-order condition for maximum is

$$
-2\left(\alpha H^{\prime} \frac{d \Delta}{d l}+\frac{1-\alpha}{2} f\right)+\left(\alpha H^{\prime \prime} \frac{d \Delta}{d l}+\alpha H^{\prime} \frac{d^{2} \Delta}{d l^{2}}+\frac{1-\alpha}{4} f^{\prime}\right)(r-l) \leq 0 .
$$

Since $r-l \leq 1$, this is fulfilled if

$$
-2\left(\alpha H^{\prime} \frac{d \Delta}{d l}+\frac{1-\alpha}{2} f\right)+\alpha H^{\prime \prime} \frac{d \Delta}{d l}+\alpha H^{\prime} \frac{d^{2} \Delta}{d l^{2}}+\frac{1-\alpha}{4} f^{\prime} \leq 0 .
$$

Using $\frac{d \Delta}{d l}>0$ (which follows from $\psi^{\prime}>0$ ), we get

$$
\frac{(1-\alpha)}{\alpha}\left(\frac{f^{\prime}}{4}-f\right)+H^{\prime} \frac{d \Delta}{d l}\left(\frac{\frac{d^{2} \Delta}{d l^{2}}}{\frac{d \Delta}{d l}}+\frac{H^{\prime \prime}}{H^{\prime}}-2\right) \leq 0 .
$$

A sufficient condition for this to be fulfilled is that

$$
\frac{f^{\prime}}{f}<4, \quad \text { and } \quad \frac{d^{2} \Delta}{d l^{2}} / \frac{d \Delta}{d l}+\frac{H^{\prime \prime}}{H^{\prime}}<2 .
$$

This condition is fulfilled if $H^{\prime \prime}=0$ and $\psi^{\prime \prime}=0$. To see this,

$$
\frac{d^{2} \Delta}{d l^{2}} / \frac{d \Delta}{d l}=\frac{\Delta^{\prime \prime}}{\Delta^{\prime}}+\frac{\partial^{2} v}{\partial l^{2}} / \frac{\partial v(l, r)}{\partial l} .
$$

Using (5) we get

$$
\begin{aligned}
\frac{\partial^{2} v}{\partial l} & =\frac{\frac{1-\alpha}{4} f^{\prime}\left(1-\alpha H^{\prime} \Delta^{\prime}\right)+\frac{1-\alpha}{2} \alpha f \Delta^{\prime \prime} H^{\prime} \frac{\partial v}{\partial l}+\left(\Delta^{\prime}\right)^{2} H^{\prime \prime} \frac{\partial v}{\partial l}}{\left(1-\alpha H^{\prime} \Delta^{\prime}\right)^{2}} \\
& =\frac{\frac{1-\alpha}{4} f^{\prime}}{\left(1-\alpha H^{\prime} \Delta^{\prime}\right)}<\frac{(1-\alpha) f}{1-\alpha H^{\prime} \Delta^{\prime}}=2 \frac{\partial v}{\partial l},
\end{aligned}
$$

where the first equality follows from the assumption that $H^{\prime \prime}=0$ and $\psi^{\prime \prime}=0$, so that $\Delta^{\prime \prime}=0$. The inequality follows from the assumption that $f^{\prime} / f<4$. Clearly, (A2) then is fulfilled. Finally, if $\frac{d \Delta}{d l}=0$, the second-order condition is fulfilled if $f^{\prime} / f<4$. 


\section{References}

AUSTEN-SMITH, D. (1987) Interest groups, campaign contributions, and probabilistic voting, Public Choice 54,123-139.

AUSTEN-SMITH, D. (1997) Interest groups: Money, information, and influence, in Perspectives on Public Choice: A Handbook, D. C. Mueller, ed. Cambridge: Cambridge University Press, 296-321.

BARON, D. P. (1994) Electoral competition with informed and uninformed voters, American Political Science Review 88, 33-47.

BILLE, L. (1997) Partier i forandring. Odense Universitetsforlag.

GROSSMAN, G. M., and E. HELPMAN (1996) Electoral competition and special interest politics, Review of Economic Studies 63, 265-286.

GROSSMAN, G. M., and E. HELPMAN (2001) Special Interest Politics. Cambridge and London: MIT Press.

HOLBROOK, T. M. (1996) Do Campaigns Matter? Thousand Oaks: Sage Publications.

LE DUC, L., R. G. NIEMI, and P. NORRIS, eds. (1996) Comparing Democracies. Elections and Voting in Global Perspective. Thousand Oaks: Sage Publications.

MAIR, P. (1994) Party organizations: From civil society to the public, in How Parties Organize: Change and Adaptation in Party Organization in Western Democracies, R. S. Katz and P. Mair, eds. Sage Publications.

MCKELVEY, R., and P. ORDESHOOK (1987) Elections with limited information: A multidimensional model, Mathematical Social Science 14,77-99.

MUELLER, D. C., and T. STRATMAN (1994) Informative and persuasive campaigning, Public Choice 81, 55-77.

MORTON, R., and C. M. CAMERON (1992) Elections and the theory of campaign contributions: A survey and critical analysis, Economics and Politics 4,79-108.

ORTUNO-ORTIN, I., and C. SCHULTZ (2000) Public funding of political parties, CES-ifo Working Paper No. 368.

PERSSON, T., and G. TABELLINI (2000) PoliticalEconomics, ExplainingEconomic Policy. Cambridge and London: MIT Press.

ROEMER, J. E. (1994) A theory of policy differentation in single issue electoral politics, Social Choice and Welfare 11, 355-380.

WITTMAN, D. (1990) Spatial strategies when candidates have policy preferences, in Advances in the Spatial Theory of Voting, J. Enelow and M. Hinich, eds. Cambridge: CUP.

ZALLER, J. R. (1992) The Nature and Origins of Mass Opinion. Cambridge: Cambridge University Press. 